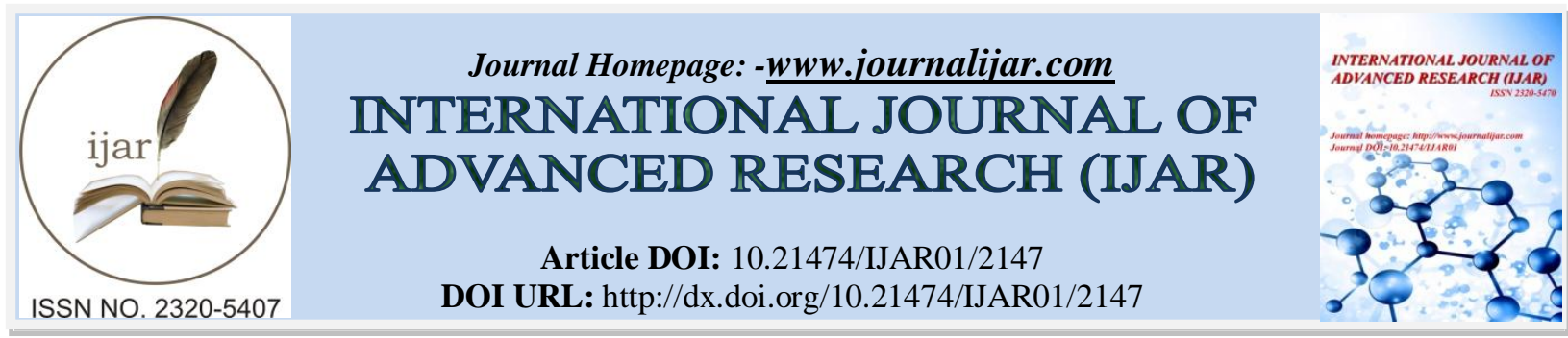

RESEARCH ARTICLE

\title{
HYBRID INTELLIGENT CONTROLLING ACTION IN COLD FLUID OUTFLOW TEMPERATURE OF SHELL AND TUBE HEAT EXCHANGERS.
}

Masoud Abedinifar.

Department of Mechatronics Engineering, Tabriz Branch, Islamic Azad University, Tabriz, Iran.

\section{Manuscript Info}

Manuscript History

Received: 25 September 2016

Final Accepted: 27 October 2016

Published: November 2016

Key words:-

Hybrid Intelligent Controller, Cold Fluid Outlet, Shell and Tube Heat Exchangers,

Simulink.

\section{Abstract}

This paper presents new approach of designing and running hybrid intelligent Controller for controlling temperature of cold fluid outflow in shell and tube heat exchangers. The proposed approach employs PID based fuzzy controller for determination of the optimal results. Results show that the proposed scheme significantly improves the performance of the shell and tube heat exchangers. It is anticipated that designing of PID based fuzzy controller using intelligent techniques would remarkably improves the rate of response of the system, maximum overshoot and settling time would be decreased in designed intelligent controller. The model is simulatedand implemented using Simulink/MATLAB.

Copy Right, IJAR, 2016,. All rights reserved.

\section{Introduction:-}

Heat exchangers are devices that are used to transfer enthalpy between two or more fluids, between a solid surface and a fluid, or between solid particulates and a fluid, at different temperatures [1]. There are different types of heat exchanger used in the industry but most of the industry use shell and tube type heat exchanger. It consists of parallel tubes enclosed in a shell. There is a variety of application of heat exchanger system. Some of the applications include electronic cooling, refrigeration and air conditioning, manufacturing, and power generation. In each of these cases, the purpose of the heat exchanger is to maintain a specific temperature condition, which is achieved by controlling the outflow temperature of one of the fluids in response to variations of the operating conditions [2]. This research paper considers a shell and tube heat exchanger and builds a single input single output model of the system with the help of experimental data available. To achieve the desired control objective and implement human intelligence in controller architecture a PID based fuzzy logic controller is designed and implemented. All the system level simulation and controller design in this paper are carried out in Simulink.

\section{Material and Methods:-}

\section{Heat exchanger system:-}

A typical chemical process for heating consists of a chemical reactor and a shell and tube heat exchanger system. The heat exchanger heats up the cold fluid to a desired point using super-heated steam supplied from the boiler. The storage tank provides cold fluid in $32^{\circ} \mathrm{C}$ using a pump and one-way valve. The super-heated steam comes from the boiler and flows through the shell side, whereas, the cold fluid flows through the tube side of the shell and tube heat exchanger system. After the steam heats up the cold fluid, the condensed steam at $93^{\circ} \mathrm{C}$ goes out of the steam trap. Consequently, the heat exchanger heats up the cold fluid to a temperature of $52^{\circ} \mathrm{C}$. The control objective is to control the temperature of the outlet cold fluid.

Corresponding Author:-Masoud Abedinifar.

Address:-Department of Mechatronics Engineering, Tabriz Branch, Islamic Azad University, Tabriz, Iran. 
The scheme of a simple shell and tube heat exchangeris shown in figure 1 [3].

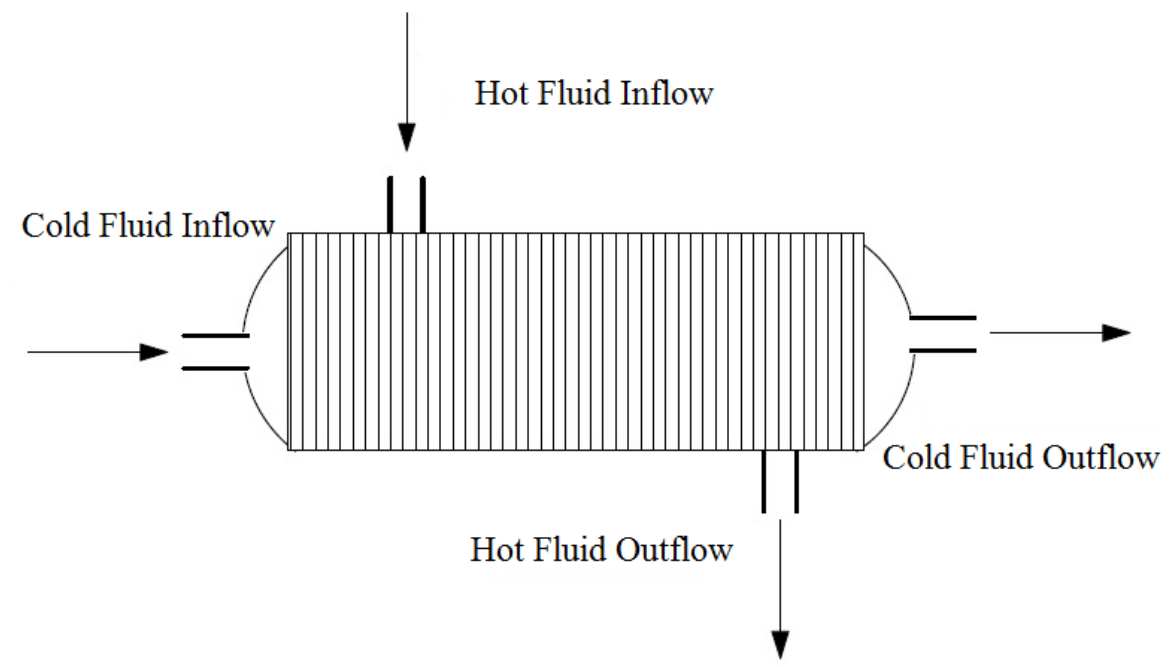

Figure 1:- The scheme of simple shell and tube heat exchanger system

Different assumptions have been considered in present work. The first assumption is that the inflow and the outflow rate of fluid are same. The second is that the heat storage capacity of the insulating wall is negligible.

\section{Feedback scheme of heat exchangers:-}

The feedback control scheme adopted in heat exchangeris shown in figure 2. Thermocouple, sensing element, is implemented in the Feedback path of the control architecture [4]. The temperature of the outgoing fluid is measured by the thermocouple and the output of the thermocouple is sent to the transmitter unit, which eventually converts the thermocouple output to a standardized signal in the range of 4-20mA. Output of the transmitter unit is given to the controller unit. The controller implements the control algorithm, compares the output with the set point and then gives necessary command to the final control element via the actuator unit. The actuator unit is a current to pressure converter and the final control unit is an air to open valve. The actuator unit takes the controller output in the range of $4-20 \mathrm{~mA}$ and converts it in to a standardized pressure signal in the range of 3-15 psig. The valve actuates according to the controller decisions.

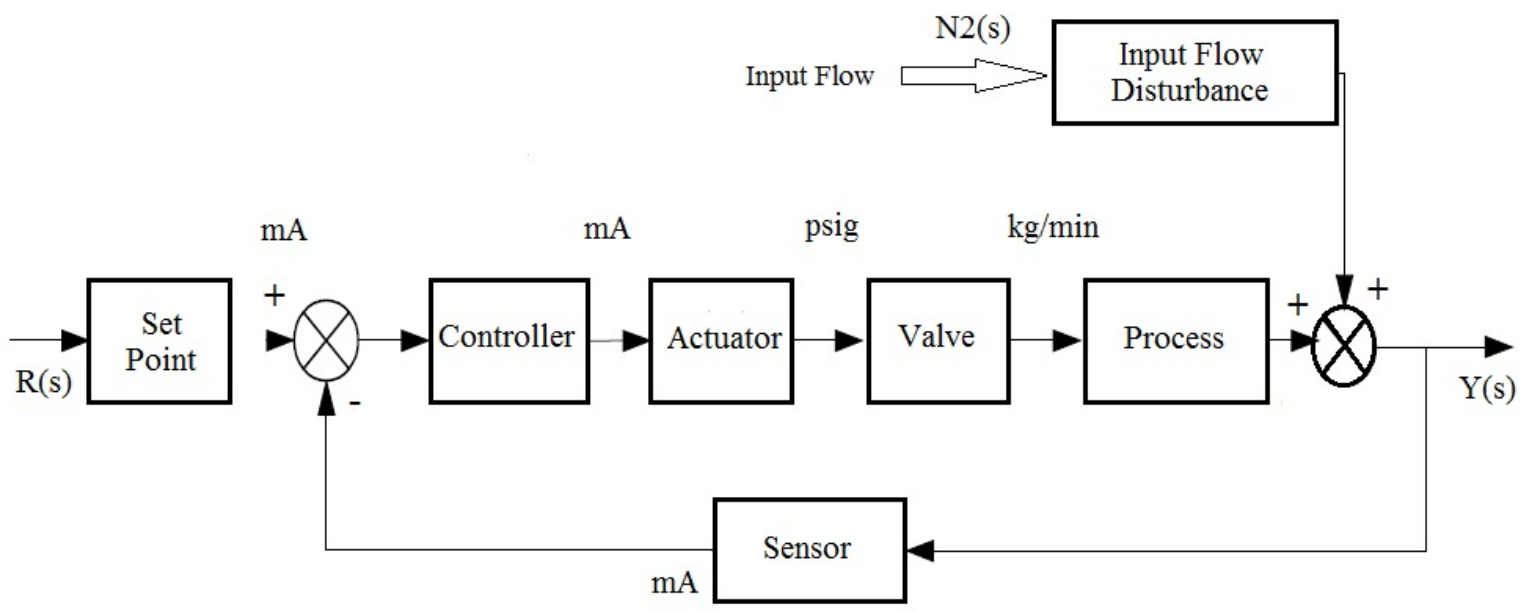

Figure 2:- Shell and tube heat exchanger's feedback control scheme

The block diagram of feedback control of shell and tube heat exchanger system including process, controller, actuator, control valve, sensor, set point and the disturbance of the processis shown in figure 3 . There are two types of disturbances in this process, one is the flow variation ofinput fluid, and the second is the temperature variation of input fluid which has significant effect compared to first one. 


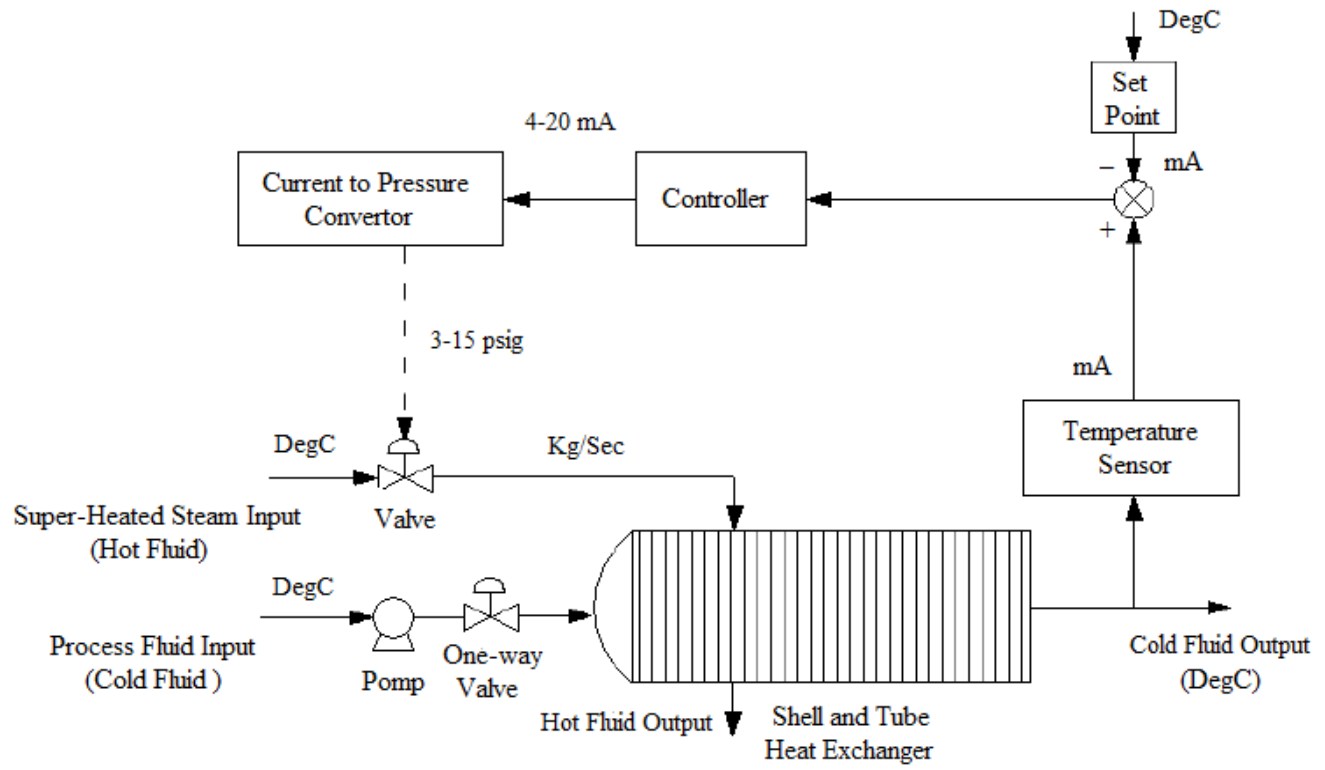

Figure 3:- Block diagram of feedback control of shell and tube heat exchanger [4]

\section{Mathematical modeling:-}

For mathematical modeling, the heat exchanger system, actuator, valve, sensor are modeled using the available experimental data. The experimental process data is summarized in table 1 [5].

Table1:- Experimental data of heat exchanger control process

\begin{tabular}{|l|l|}
\hline Heat exchanger response to the steam flow gain & $50^{\circ} \mathrm{C} /(\mathrm{kg} / \mathrm{sec})$ \\
\hline Time constants & $30 \mathrm{sec}$ \\
\hline The current range of actuator & $4-20 \mathrm{~mA}$ \\
\hline The pressure range of actuator & $3-15 \mathrm{psig}$ \\
\hline Control valve capacity & $1.6 \mathrm{~kg} / \mathrm{sec}$ \\
\hline Time constant of control valve & $3 \mathrm{sec}$ \\
\hline The range of temperature sensor & $50-150^{\circ} \mathrm{C}$ \\
\hline Time constant of temperature sensor & $10 \mathrm{sec}$ \\
\hline
\end{tabular}

The transfer functions of different part of the feedback control of shell and tube heat exchanger system and related gains are shown in table 2 [5].

Table 2:- Transfer functions and gains

\begin{tabular}{|l|l|}
\hline Process transfer function & $\frac{50 e^{-s}}{30 s+1}$ \\
\hline Transfer function of valve & $\frac{0.13}{3 s+1}$ \\
\hline Gain of current to pressure convertor & 0.75 \\
\hline Transfer function of disturbance & $\frac{1}{30 s+1}$ \\
\hline Transfer function of temperature sensor & $\frac{0.16}{10 s+1}$ \\
\hline Gain of valve & 0.13 \\
\hline
\end{tabular}


The transfer function model of the feedback control of shell and tube heat exchanger systemis shown in figure 4 .

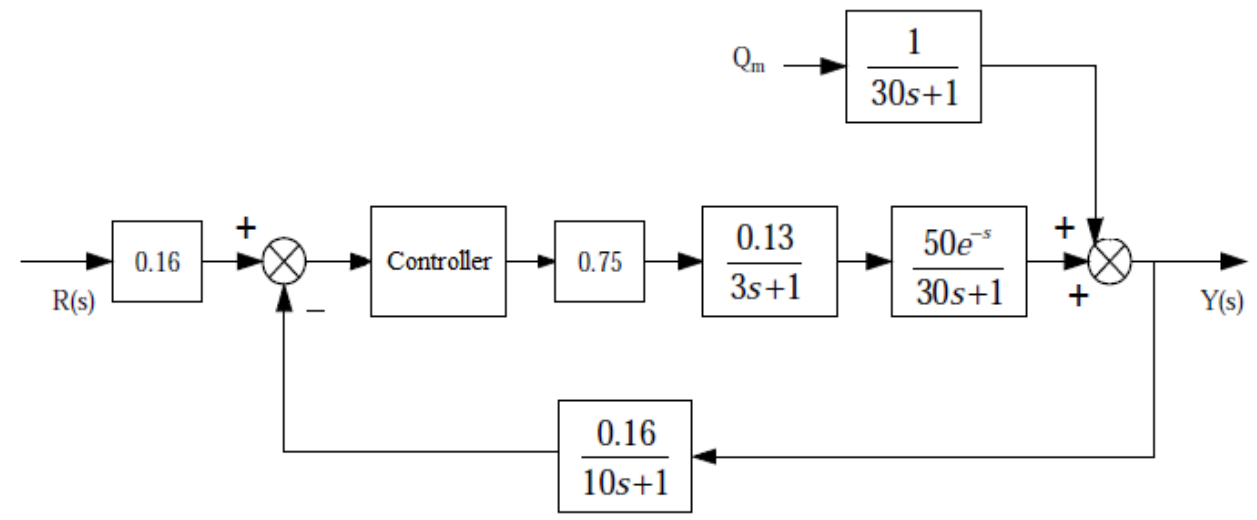

Figure 4:- Transfer function model of heat exchanger system[4]

\section{Results and Discussion:-}

After mathematical simulation, in order to control the outlet temperature of shell and tube heat exchanger, fuzzy PID controller is designed and implemented. PID controller is a standard control structure for classical control theory. But the performance is greatly distorted and the efficiency is reduced due to nonlinearity in the process plant. The fuzzy PID controllers are the natural extension of their conventional version, which preserve their linear structure of PID controller. The fuzzy PID controllers are designed using fuzzy logic control principle in order to obtain a new controller that possesses analytical formulas very similar to digital PID controllers. Fuzzy PID controllers have variable control gains in their linear structure. These variable gains are non-linear function of the errors and changing rates of error signals. The main contribution of these variable gains in improving the control performance is that they are self-tuned gains and can adapt to rapid changes of the errors and rate of change of error caused by time delay effects, nonlinearities and uncertainties of the underlying process [6].By using available experimental data, the PID based fuzzy controller is designed in Simulink/MTLAB.

The Simulink scheme for temperature control of shell and tube heat exchanger system with fuzzy PID controlleris shown in figure 5 .

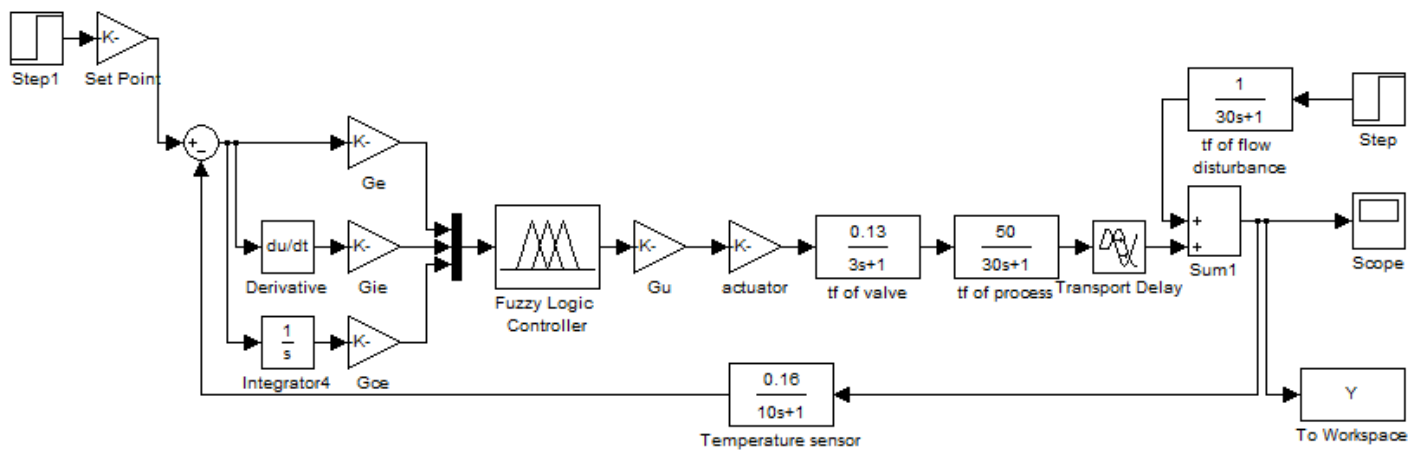

Figure 5:- Simulink scheme of PID fuzzy controller for shell and tube heat exchanger

The control tuning of the PID fuzzy based Sugeno controller depends on the trial and error to find the scaling factors for each variable. The best values of the scaling factors were tuned using Simulink. Input scaling factors are Ge, Gie and Gce which are respectively obtained $0.33,0.22$ and 0.11 , and also the output scaling factor, Gu, is obtained 1 . The inputs of PID fuzzy control are defined as the proportional gain $(\mathrm{Kc})$, integral gain $(\mathrm{Ki})$ and derivative gain $(\mathrm{Kd})$. The output variable is called the control action (u). Fuzzy sets are defined for each input and output variable. There are three fuzzy levels: negative $(\mathrm{N})$, zero $(\mathrm{Z})$ and positive $(\mathrm{P})$. 
The Sugeno based fuzzy inference system with three inputs is shown in figure 6 .

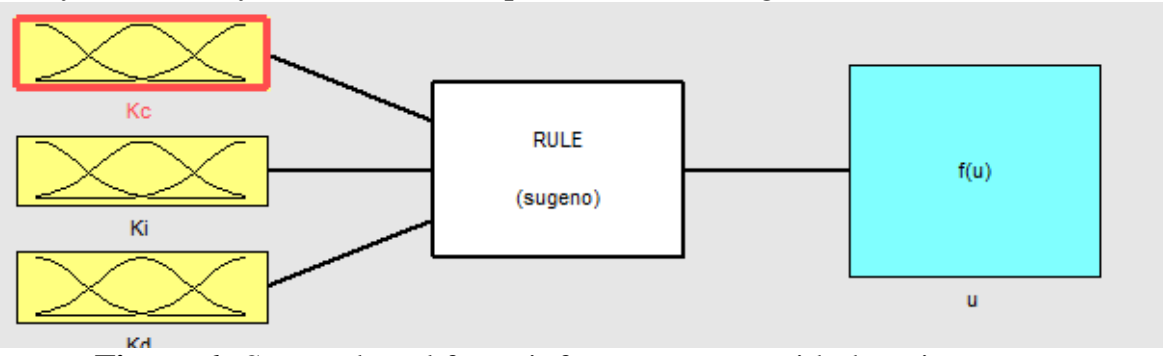

Figure 6:-Sugeno based fuzzy inference system with three inputs

The membership function for the input $1(\mathrm{Kc})$ is shown in figure 7. By trial and error the proportional gain has a range of $[-1,1]$.

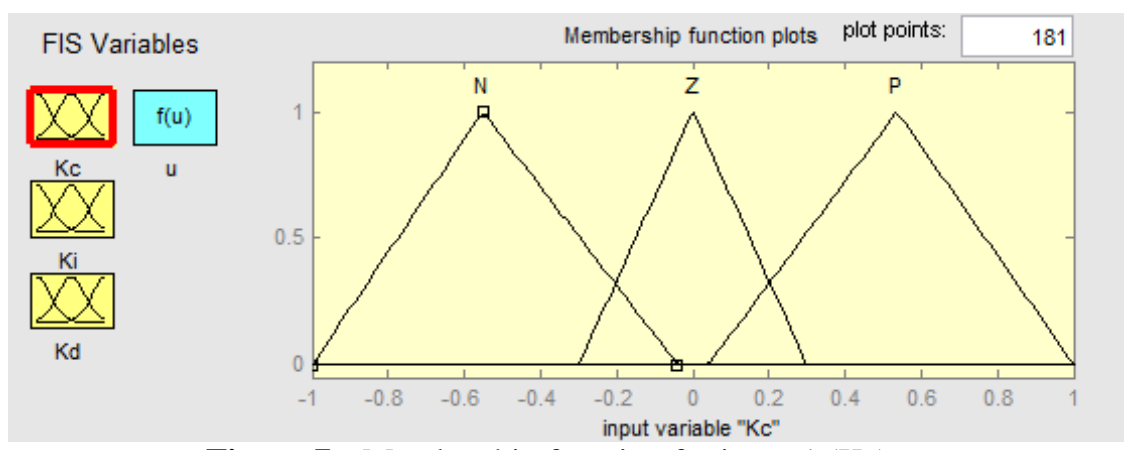

Figure 7:- Membership function for input $1(\mathrm{Kc})$

The membership function for the input 2 (Ki) is shown in figure 8. By trial and error the integral gain has a range of $[-2,2]$.

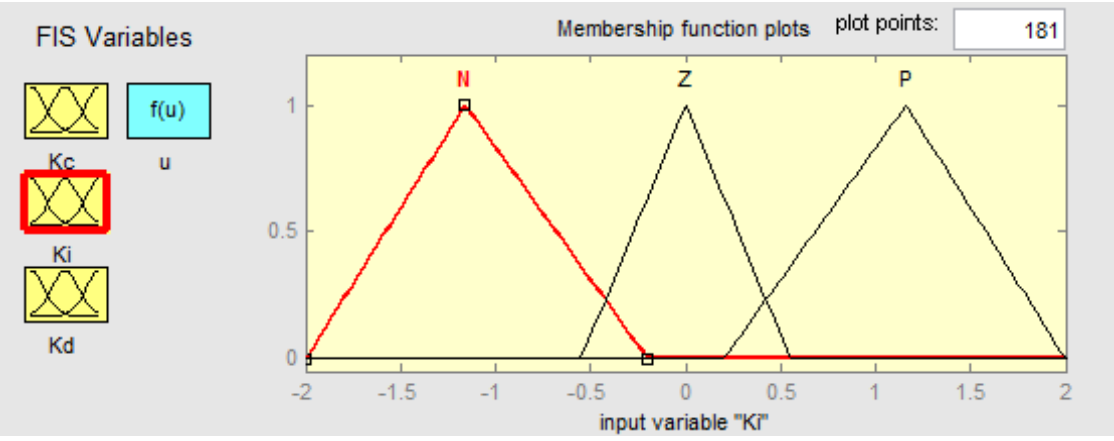

Figure 8:- Membership function for input $2(\mathrm{Ki})$

The membership function for the input $3(\mathrm{Kd})$ is shown in figure 9. By trial and error the derivative gain has a range of $[-1,1]$.

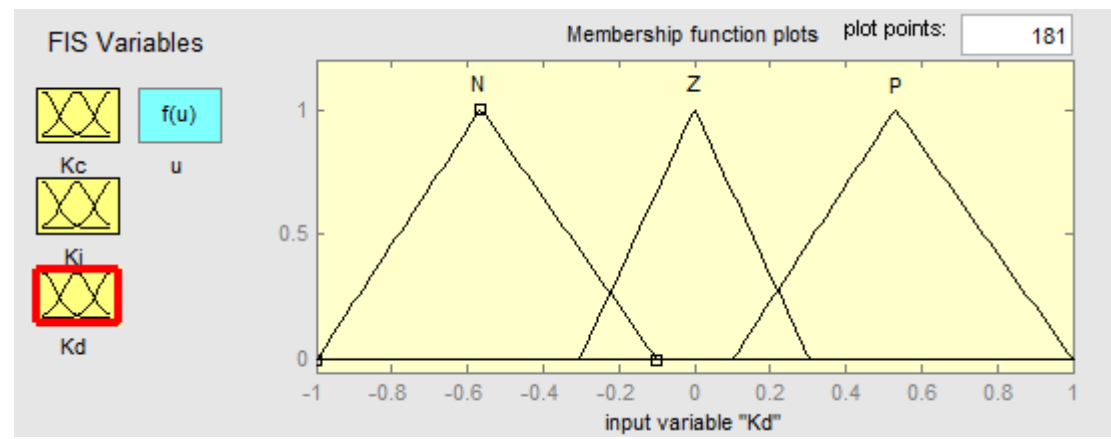

Figure 9:- Membership function for input $3(\mathrm{Kd})$ 
The rule base of PID fuzzy controller is shown in figure 10.

\begin{tabular}{|c|c|c|c|c|c|c|c|c|c|c|}
\hline \multicolumn{2}{|c|}{$\mathrm{u}(\mathrm{t})$} & \multicolumn{9}{|c|}{$\mathrm{Ki}$} \\
\hline & & $\mathrm{N}$ & $\mathrm{N}$ & $\mathrm{N}$ & $Z$ & $Z$ & Z & $P$ & $P$ & $\mathrm{P}$ \\
\hline \multirow{3}{*}{$\mathrm{Kc}$} & $\mathrm{N}$ & $\mathrm{P}$ & $P$ & $P$ & $P$ & $P$ & Z & $P$ & $Z$ & $\mathrm{~N}$ \\
\hline & $Z$ & $\mathrm{P}$ & $\mathrm{P}$ & Z & $\mathrm{P}$ & Z & $\mathrm{N}$ & $Z$ & $\mathrm{~N}$ & $\mathrm{~N}$ \\
\hline & $P$ & $\mathrm{P}$ & Z & $\mathrm{N}$ & Z & $\mathrm{N}$ & $P$ & $\mathrm{~N}$ & $\mathrm{~N}$ & $\mathrm{~N}$ \\
\hline & & $\mathrm{N}$ & Z & $\mathrm{P}$ & $\mathrm{N}$ & Z & $P$ & $\mathrm{~N}$ & $Z$ & $P$ \\
\hline & & \multicolumn{9}{|c|}{$\mathrm{Kd}$} \\
\hline
\end{tabular}

Figure 10:- The rule base of PID fuzzy controller

Performance evaluation scheme of controller is done using time response analysis. In time response analysis unit step response of the PID fuzzy controller is evaluated and maximum overshoot and settling time is calculated. The unit step response of shell and tube heat exchanger using PID fuzzy controller is shown in figure 11.

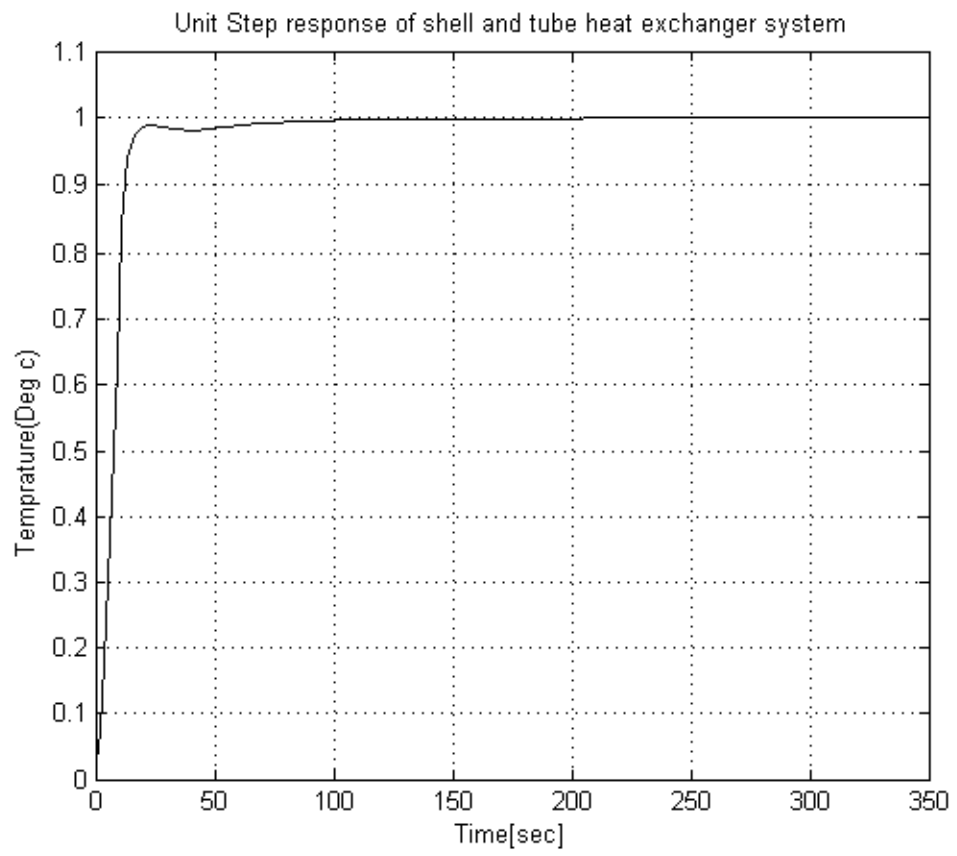

Figure 11:- Unit step response of shell and tube heat exchanger

To evaluate the performance of the controller, in step response analysis different parameters are considered. From those parameters there are two most important parameters. The first parameter is the maximum overshoot and the second parameter is the settling time.

Maximum overshoot indicates the normalized difference between the time response peak and steady output [7]. It is defined as:

$\% M_{P}=\frac{C\left(t_{p}\right)-C(\infty)}{C(\infty)} * 100 \%$

Settling time is the time required for the response to reach and stay within a specified tolerance band of its final value (approximately 2-5\% final value) [7]. The tolerance band is taken randomly as 5\%.

By analyzing a unit step response of this control system, settlement time is 51.469 seconds, and maximum overshootis $0 \%$. 
Finally, performance indices are used in order to evaluate controller's performance. A system is considered as anoptimum control system when the system parameters are adjusted so that the index reaches an extreme, commonly a minimum value. To be useful a performance, indices must be the numbers that are always positive or zero. Then the best system is defined as the system that minimizes the indices. There are different performance indices of a control system and most common performance indices are IAE (integral absolute error), ISE (integral square error), ITAE (integral time absolute error) and ITSE (integral time square error) [7]. Stated performance indices will be obtained by these formulas:

$$
\begin{aligned}
\text { IAE }= & \int_{0}^{\infty}|e(t)| d t(2) \\
\text { ISE }= & \int_{0}^{\infty} e^{2}(t) d t(3) \\
& \\
\text { ITAE }= & \int_{0}^{\infty} t|e(t)| d t(4) \\
& 0 \\
\text { ITSE }= & \int_{0}^{\infty} t e^{2}(t) d t(5)
\end{aligned}
$$

The obtained performance indices of the designed PID fuzzy controller are shown in table 3 .

Table 3:- Performance indices of designed PID fuzzy controller

\begin{tabular}{|l|l|l|l|l|}
\hline Controller & IAE & ISE & ITAE & ITSE \\
\hline PID Fuzzy & 2.887 & 0.286 & 46.96 & 2.469 \\
\hline
\end{tabular}

\section{Conclusions:-}

The aim of the proposed controller is to regulate the temperature of the outgoing fluid of a shell and tube heat exchanger system to a desired temperature in the shortest possible time and minimum overshoot irrespective of step change in load and process disturbances, equipment saturation and non-linearity of different control equipment. After time response based analysis carried out, it is observed that the intelligent PID fuzzy controller provides a satisfactory performance in both steady state and transient state. By controlling output fluid temperature in shell and tube heat exchangers in effective way, we can achieve a significant amount of energy saving. For future research, other control systems based genetic algorithm will be designed and implemented.

\section{References:-}

1. Ramesh, K., and Dusan, P., Fundamentals of heat exchanger design, John Willey and Sons, USA, 2003, 103112.

2. Kaddour, N., Process modeling and control in chemical engineering. Marcel Dekker Inc., New York, 1989, 186-192.

3. Anton, S., "Some aspect of Modeling shell and tube heat exchangers," Proceedings of 7th Modelica Conference, 716-72. Sep 2009.

4. Orlando, D., Nibaldo, R., and Luiz, A., "Neural networks for cost estimation of shell and tube heat exchangers". International Multi Conference of Engineers and Computer Scientists, 2 (1). 1584-1589, March 2008.

5. Gopal, M., Control systems principles and design. Tata McGraw-Hill Education, New York, 2008, 245-250.

6. O. Ursaru, M. Lucanu and L. Tigaeru, "A hybrid PID-fuzzy controller for dc/dc converters". Signals, Circuits and Systems, Vol. 1, pp. 97-100, 2003.

7. M. Kenneth and V. Wim, Management Control Systems: Performance Measurement, Evaluation and Incentives. Prentice Hall, pp. 109-119, 2007. 